\title{
Correction to: Bioanalytical Applications of Microextraction Techniques: A Review of Reviews
}

\author{
Vahid Jalili ${ }^{1}$. Abdullah Barkhordari ${ }^{2}$. Alireza Ghiasvand $d^{3,4}$
}

Published online: 13 April 2020

๑) Springer-Verlag GmbH Germany, part of Springer Nature 2020

\section{Correction to: Chromatographia}

https://doi.org/10.1007/s10337-020-03884-1

In the original publication, the phrase "Liquid phase" in Table 1 column 1 was included in the wrong line. The phrase needs to be included in row 13 in front of LPME.

In reference No. 25, the correct spelling is " $n$-Hexane in air samples". The original publication of the article has been updated to reflect the change.

Publisher's Note Springer Nature remains neutral with regard to jurisdictional claims in published maps and institutional affiliations.

The original article can be found online at https://doi.org/10.1007/ s10337-020-03884-1.

Abdullah Barkhordari

A.Barkhordari2007@gmail.com; Barkhordari@shmu.ac.ir

1 Student Research Committee, Department of Occupational Health Engineering, School of Public Health and Safety, Shahid Beheshti University of Medical Sciences, Tehran, Iran

2 Department of Occupational Health Engineering, School of Public Health, Shahroud University of Medical Sciences, Shahroud, Iran

3 Australian Centre for Research on Separation Science (ACROSS), School of Natural Sciences, University of Tasmania, Hobart, TAS 7001, Australia

4 Department of Chemistry, Lorestan University, Khorramabad, Iran 